\title{
Prognostic value of the ALBI grade among patients with single hepatocellular carcinoma without macrovascular invasion
}

\section{Wenhao Chen}

The Second Xiangya Hospital, Central South University

\section{Zijian Zhang}

The Second Xiangya Hospital of Central South University

\section{Huan Wang}

Central South University of Second Xiangya Hospital

\section{Li Xiong}

The Second Xiangya Hospital, Central South University

\section{Yu Wen}

The Second Xiangya Hospital, Central South University

\section{Jiangjiao Zhou}

The Second Xiangya Hospital, Central South University

\section{Fanhua Kong}

The Second Xiangya Hospital of Central South University

\section{Heng Zou ( $\nabla$ zhcsuxy@csu.edu.cn )}

The Second Xiangya Hospital, Central South University

\section{Research article}

Keywords: Hepatocellular carcinoma, Overall survival, Tumor size, Albumin-bilirubin grade

Posted Date: October 5th, 2020

DOI: https://doi.org/10.21203/rs.3.rs-30583/v2

License: (1) This work is licensed under a Creative Commons Attribution 4.0 International License. Read Full License

Version of Record: A version of this preprint was published at Medicine on June 18th, 2021. See the published version at https://doi.org/10.1097/MD.0000000000026265. 


\section{Abstract}

Background: Although evidence for the application of albumin-bilirubin (ALBI) grading system to assess liver function in hepatocellular carcinoma (HCC) is available, less is known whether it can be applied to determine the prognosis of single HCC with different tumor sizes. This study aimed to address this gap.

Methods: Here, we enrolled patients who underwent hepatectomy due to single HCC from the year 2010 to 2014. Analyses were performed to test the potential of ALBI grading system to monitor the long-term survival of single HCC subjects with varying tumor sizes.

Results: Overall, 265 participants were recruited. The overall survival (OS) among patients whose tumors were $\leq 7 \mathrm{~cm}$ was remarkably higher compared to those whose tumors were $>7 \mathrm{~cm}$. The Cox proportional hazards regression model identified the tumor differentiation grade, ALBI grade, and maximum tumor size as key determinants of the OS. The ALBI grade could stratify the patients who had a single tumor $\leq$ $7 \mathrm{~cm}$ into two distinct groups with different prognoses. The OS between ALBI grades 1 and 2 was comparable for patients who had a single tumor $>7 \mathrm{~cm}$.

Conclusions: We show that ALBI grading system can predict disease outcomes of single HCC patients with tumor size $\leq 7 \mathrm{~cm}$. However, the ALBI grade may not predict capability the prognosis of patients with single tumor $>7 \mathrm{~cm}$.

\section{Background}

Hepatocellular carcinoma (HCC) is a very aggressive form of cancer. Current statistics rank HCC as the sixth most prevalent cancer disease in the world. Also, cancer has been reported to be the $3^{\text {rd }}$ most prevalent cause of cancer-associated deaths worldwide[1]. Treatment of HCC has remained a challenge to date. When diagnosed early, resection can be performed to get rid of the affected part then other therapeutic options like chemotherapy and radiotherapy can be used to kill the tumors that could have metastasized. Therefore, surgical resection is still the main treatment option for single HCC[2]. However, because this form of tumor is very aggressive, recurrence is common even after surgical resection; hence very early diagnosis is necessary to ensure successful treatment and to improve the disease outcome.

The guidelines of Barcelona Clinic for Liver Cancer (BCLC) staging system stipulates that hepatic surgery is only suitable for early-stage tumors (stages 0 and $A$ : single tumors or multinodular tumors with size $\leq$ $3 \mathrm{~cm}$, Child-Pugh A or B, PS 0 , and $\leq 3$ nodules with no vascular invasion)[3]. The size of a tumor is a significant determinant of disease outcomes of HCC patients. A tumor with large diameter correlates with worse clinical outcomes in HCC patients[4, 5]. Johnson et al. put forward a novel way of assessing the function of the liver termed the albumin-bilirubin (ALBI) grade. This has been verified to be an ideal tool for evaluating the liver function of HCC patients. The model involves the use of only serum albumin and bilirubin and avoids subjective parameters like ascites and encephalopathy[6]. The ALBI grade was verified as a precise prognostic model for advanced HCC patients and receiving sorafenib[7], for solitary HCC within the Milan criteria[8], for early-stage HCC patients who have treated by radiofrequency 
ablation[9], and for different BCLC stages of HCC[10]. However, the association between the size of single tumors of HCC patients and the ALBI grade is not sufficiently understood.

Herein, we examined the potential of ALBI grade to assess the clinical outcomes of HCC with varying tumor sizes.

\section{Methods}

\section{Patients}

Hepatocellular carcinoma (HCC) patients who received hepatectomy in our ward from 2010 through 2014 were recruited. The HCC was diagnosed by pathological examination of prepared liver specimens by a qualified pathologist. Only patients who had the following features were included in the study: ALBI grade 1 or 2 for liver function; no treatment for HCC before hepatectomy, single tumor without macrovascular invasion, and absence of lymph node metastasis. The patients were classified into subgroups on the basis of the size of tumors: group I, tumor sizes $\leq 3 \mathrm{~cm}$; group II, tumor sizes $>3$ and $\leq 5 \mathrm{~cm}$; group III, sizes $>5$ and $\leq 7 \mathrm{~cm}$; group IV, tumor size $>7$ and $\leq 10 \mathrm{~cm}$; group $V$, tumor size $>10 \mathrm{~cm}$.

\section{Definitions}

We calculated the ALBI scores as follows: ALBI score $=0.66 \times \log _{10}$ (total bilirubin, $\mu \mathrm{mol} / \mathrm{I}$ ) $-0.085 \times$

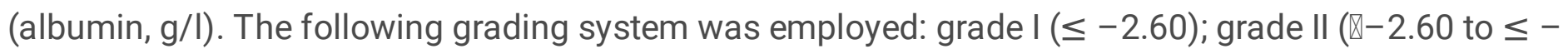
1.39); grade III ( $(-1.39)[6]$. The Cancer of the Liver Italian Program (CLIP) staging system consists of four variables: Child-Pugh grade, tumor morphology, alpha-fetoprotein (AFP) and portal vein thrombosis[11].

A postoperative complication was defined according to the Dindo-Clavien classification[12]. Postoperative mortality was defined as death within 60 days after surgery.

\section{Surgical methods}

Indocyanine green test was carried out to assess liver function in hepatitis B virus (HBV) or hepatitis C virus infected individuals before the surgery. Preoperative remnant liver volume was mainly assessed by three-dimensional reconstruction and virtual hepatic resection among patients who underwent a major hepatectomy as per the methods described previously[13]. Most of the patients received open hepatectomy through the right subcostal margin incision. However, a few selective patients (those with tumor size $<5 \mathrm{~cm}$ positioned in segments $2-6$ of the liver) underwent laparoscopic surgery. Intraoperative ultrasonography was conducted to confirm the relationship between tumors and vessels and locate the satellite nodules when necessary. After determining resectability, anatomical liver resection was the preferred option in the case of sufficient future remnant liver functional reserve. Hepatectomy extent was considered minor resection or major (involving three/more Couinaud liver segments) and minor[14]. 
Follow-up periods were one month after discharge and every three months for the next two years. During the follow-ups, routine tests on blood, AFP, imaging examinations, such as ultrasonography, contrastenhanced CT/MRI, and liver function tests were performed. In the case of recurrence, the patients were taken through repeated hepatic resection, transcatheter arterial chemoembolization, ablation, or systemic therapies. These therapies were administered based on the hepatic function, tumor status, and the economic status of the patient. The overall survival (OS) was measured beginning from the first diagnosis of HCC (admission date) until last follow-up/death/January 2018.

\section{Data analysis}

Data involving continuous variables were assessed by the Mann-Whitney and $U$ test and shown as Interquartile range whereas discrete variables were analyzed by Chi-square. Kaplan-Meier (KM) plot was employed in the determination of overall survival. The log-rank test was employed to make comparisons of survival rates. The multivariate Cox proportional hazard regression model was applied identify independent prognostic factors for overall survival. The area under the receiver operating characteristic (ROC) curve was used to measure the discriminatory power of the staging systems as predictors of survival. These analyses were conducted using SPSS v25.0. A $P<0.05$ represented statistically significant differences.

\section{Results}

\section{Clinicopathological features}

Precisely $265 \mathrm{HCC}$ patients, including 231 males and 34 females (median age $=51 \mathrm{yrs)}$ [range: $21-77 \mathrm{yrs}$ ] were enrolled. A total of $60,62,46,52$, and 45 patients were classified in groups I, II, III, IV, and V, respectively. Those whose tumors were $\leq 7 \mathrm{~cm}$ presented a higher albumin level, a longer survival time, and a higher proportion of ALBI grade $2 \mathrm{HCC}$ than those who had tumors that were $>7 \mathrm{~cm}(P=0.010$, $P<0.001 \& P=0.036$, respectively). However, patients who had tumor size $\leq 7 \mathrm{~cm}$ had a significantly low platelet count, a small tumor size, a short operative time, low blood loss, low rates of ALBI grade $1 \mathrm{HCC}$, AFP $\geq 400 \mathrm{ng} / \mathrm{mL}$, major liver resection, and poor differentiation $(P<0.001, P<0.001, P=0.015, P<0.001$, $P=0.036, P=0.013, P<0.001, \& P=0.015$, respectively). The baseline features of participants are presented in Table 1.

Of the 265 patients, 95 (35.8\%) experienced postoperative complication, including grade I complication in $30(11.3 \%)$ patients, grade II complication in 49 (18.5\%) patients, grade III complication in $13(4.9 \%)$ patients, grade IV complication in $3(1.1 \%)$ patients. Two patients died within 60 days after surgery, with a postoperative mortality rate of $0.75 \%$.

\section{Survival}

Among the 265 patients, the OS at 1 and 3 years reached $92.8 \%$ and $66.8 \%$, respectively. No considerable differences in the OS were observed between the groups I and II $(P=0.525)$, groups II and III $(P=0.439)$, 
and groups 1 and III ( $P=0.627)$ (Figure 1A). A similar OS was noted between groups IV and V $(P=0.425$, Figure 1B). However, the OS among patients with tumors size $\leq 7 \mathrm{~cm}$ was considerably longer compared to those who had tumor size $>7 \mathrm{~cm}(P<0.001$, Figure 1C).

\section{Evaluation of OS by multivariate analysis}

The Cox proportional hazards regression model assessment of the total cohort identified three indices as independent predictive factors for OS: ALBI grade (hazard ratio (HR): $2.10 ; 95 \%$ confidence interval (Cl): 1.43-3.08; $P<0.001$ ), maximum tumor size (HR: 1.72; 95\% Cl: 1.16-2.56; $P=0.007$ ), differentiation grade (HR: $1.47 ; 95 \%$ Cl: $1.01-2.15 ; P=0.045)$ (Table 2).

In the subgroup that had tumor size $\leq 7 \mathrm{~cm}$, the independent predicting factors for OS included the ALBI grade (HR: 2.37; 95\% Cl: $1.39-4.05 ; P=0.002$ ) and platelet count (HR: $1.80 ; 95 \% \mathrm{Cl}: 1.07-3.05 ; P=0.027$ ). But in the subgroup with tumor size $>7 \mathrm{~cm}, \mathrm{ALBI}$ grade was not identified as a major determinant of OS (Table 3).

\section{Comparison of overall survival of patients with ALBI grades 1 and $2 \mathrm{HCC}$ stratified by tumor size}

For the total cohort, we observed a remarkable difference in the OS between ALBI grades 1 and 2 patients (Figure $2 \mathrm{~F}$ ). For groups 1 , II, and III, the ALBI grade 1 patients showed a significantly longer survival relative to the ALBI grade 2 patients $(P=0.006, P=0.025$, and $P=0.039$; Figures $2 \mathrm{~A}, 2 \mathrm{~B}$, and $2 \mathrm{C}$, respectively). However, the OS was comparable between patients in ALBI grades 1 and 2 in groups IV and $\mathrm{V}(P=0.546$ and $P=0.224$; Figures $2 \mathrm{D}$ and $2 \mathrm{E}$, respectively $)$.

\section{Comparison of patients' overall survival in tumor size $\leq 7 \mathrm{~cm}+\mathrm{ALBI}$ grade $1 \mathrm{vs}$. tumor size $\leq 7 \mathrm{~cm}+$ ALBI grade 2 vs. tumor size $>7 \mathrm{~cm}$ subgroups}

Given their importance in predicting OS, we further evaluated the effects of tumor size and ALBI grade on the HCC patient prognosis. With regards to size of tumor and ALBI grade, considerable differences in the OS were observed among the three patient subgroups (Figure 3). The tumor size $\leq 7 \mathrm{~cm}+\mathrm{ALBI}$ grade 1 subgroup presented a remarkably higher OS compared to the tumor size $\leq 7 \mathrm{~cm}+\mathrm{ALBI}$ grade 2 and tumor size $>7 \mathrm{~cm}$ subgroups. The patients in the tumor size $>7 \mathrm{~cm}$ subgroup exhibited the poorest OS among the three subgroups.

\section{Discriminative ability of different scoring systems for patients' survival}

ROC curve analyses of ALBI score, Child-Pugh score and CLIP score were performed to predict 1-year survival and 3-year survival. The area under the ROC curve (AUC) for ALBI score, Child-Pugh score and CLIP score were $0.640(P=0.043), 0.590(P=0.191), 0.617(P=0.090)$ in predicting 1-year survival (Figure 4A), and $0.645(P<0.001), 0.580(P=0.034), 0.584(P=0.025)$ in predicting 3-year survival (Figure 4B).

\section{Discussion}


Herein, the effectiveness of ALBI grading system to predict the disease progress of HCC subjects with different tumor sizes was evaluated. For years, various prognostic staging systems for $\mathrm{HCC}$ has been proposed[11]. Our study showed that the ALBI score might have a better value in predicting 1-year and 3year survival than Child-Pugh score and CLIP score. Liu et al. found that the CLIP staging system was the best prognostic model in a large prospective cohort of $3182 \mathrm{HCC}$ patients among 11 currently used HCC staging systems[15]. Shao et al. proved that the ALBI-based CLIP (ALBI-CLIP) had higher R and lower AIC than CLIP, demonstrating ALBI-CLIP might have improved prognosis prediction for advanced HCC than CLIP[16]. The Japan Integrated Staging (JIS) for HCC has been extensively studied in Japanese population[17]. Hiraoka et al. demonstrated that the ALBI-based JIS (ALBI-T) offered similar or better prognostic performance than the JIS score in HCC patients $[18,19]$. More studies are needed to verify the value of combination of ALBI grade with other staging systems.

Tumor size has been regarded as one of the primary determinants of tumor recurrence and hence overall survival[4, 20]. Huang et al. identified tumor size as a major determinant of HCC patient prognosis, particularly the patients with solitary tumors without vascular invasion[21]. Another study also reported that tumor size is an independent prognostic factor of recurrence-free survival among solitary HCC patients and who received curative liver resection[22]. However, other studies showed that large HCC does not conform to BCLC staging and treatment guidelines[23, 24]. Among HCC patients at the BCLC stage A, single tumors $>5 \mathrm{~cm}$ showed similar prognosis as patients with single tumors $\leq 5 \mathrm{~cm}[25,26]$. Herein, tumor size served as an independent predictor of overall survival for single HCC without macrovascular invasion. Patients who had a tumor size $>7 \mathrm{~cm}$ exhibited a significantly poorer OS compared to those who had a tumor size $\leq 7 \mathrm{~cm}$. To further assess the tumor size effect on long-term survival, we compared the OS in subgroups divided by the tumor size. No differences were noted in the OS of groups I, II, and III. Groups IV and V exhibited a similar OS. These findings indicate that patients with tumor size $\leq 7 \mathrm{~cm}$ or tumor size $>7 \mathrm{~cm}$ may feature similar survival times. Therefore, patients who have a single tumor size $>7$ $\mathrm{cm}$ ought not to be ascribed to the same BCLC stage as those with a single tumor size $\leq 7 \mathrm{~cm}$.

Several factors may explain why patients who had a single tumor $\leq 7 \mathrm{~cm}$ showed a remarkably better OS compared to those with tumor size $>7 \mathrm{~cm}$. We observed that patients whose tumors were $>7 \mathrm{~cm}$ presented a lower albumin level, greater blood loss, and a higher proportion of serum AFP $\geq 400 \mathrm{ng} / \mathrm{ml}$ and poor differentiation than patients with tumor size $\leq 7 \mathrm{~cm}$. AFP is regarded as an important prognostic indicator for HCC undergoing liver resection[24, 27]. A high level of preoperative AFP often indicates poor survival time after surgery[28]. Tumor differentiation is positively correlated with the overall survival of HCC patients after hepatectomy[29]. In our study, poor differentiation was found to be an independent OS predictor in the multivariate analysis. The low histologic grade correlates with high risk of recurrence and low OS of HCC patients following curative resection[30].

The disease outcomes of HCC patients post-liver resection is partly affected by the existing liver physiological status. In accordance with previous studies[10, 13, 31, 32], we determined that ALBI grade could influence the OS of the total cohort and tumor size $\leq 7 \mathrm{~cm}$ subgroup. The patients who had an ALBI grade 1 presented a better survival time compared to those had an ALBI grade 2 in the total cohort. We 
analyzed the ALBI grade in the different subgroups to further validate its value in predicting prognoses of $\mathrm{HCC}$. The OS rates were higher in ALBI grade 1 patient relative to ALBI grade 2 patients in groups I, II, and III. However, when the OS rates were analyzed in groups 4 and 5, no marked differences occurred between the subjects with ALBI grades 1 and 2. Multivariate analysis identified the lack of predictive capability of ALBI grade for the tumor size $>7 \mathrm{~cm}$ subgroup. Therefore, ALBI grade alone might be insufficient in determining the prognosis of $\mathrm{HCC}$ patients with single tumor $>7 \mathrm{~cm}$. For large $\mathrm{HCC}$, tumor burden could have a more significant function in determining the OS compared to the liver function. Microvascular invasion (MVI) is a critical risk factor for HCC prognosis[33-35]. Previous studies demonstrated that the incidence of MVI increased with tumor size[36]. In solitary HCC, the incidence of MVI progressively increased from $4.1 \%$ to $30.7 \%$ as the tumor size increased from $<2 \mathrm{~cm}$ to $8.1-9.9 \mathrm{~cm}$, to $12.8 \%$ in tumor size $\leq 5 \mathrm{~cm}$, and to $27.7 \%$ in tumor size measuring $5.1-9.9 \mathrm{~cm}^{[4]}$. Therefore, MVI might play a more crucial function in determining the prognosis compared to liver function for large single tumors.

Theoretically, the combination of tumor size and liver function could effectively predict the prognosis of HCC following hepatic resection. We integrated tumor size and ALBI grade, to generate an accurate model for determining the prognosis of patients with a single tumor. The results showed that patients in the tumor size $\leq 7 \mathrm{~cm}+\mathrm{ALBI}$ grade 1 subgroup presented a remarkably higher OS rate compared to those in the tumor size $\leq 7 \mathrm{~cm}+\mathrm{ALBI}$ grade 2 and tumor size $>7 \mathrm{~cm}$ subgroups. Patients in the single tumor $>7$ $\mathrm{cm}$ subgroup achieved the poorest OS among the three subgroups. Thus, the prognosis of a single small tumor might be remarkably affected by liver function, whereas tumor burden could play a leading role in the prognosis of single large tumors. In clinical practice, patients having a single tumor $>7 \mathrm{~cm}$ and who are undergoing liver resection may likely suffer from relapse. Thus, additional postoperative treatments may be necessary for these patients.

This study features several limitations. First, the conclusions are based on the retrospective analysis of data from a single liver center and weakened by comparably small sample size, thereby selective bias may exist. Multicenter prospective research is required to verify and extend the results of the present study. In addition, our study did not assess the influence of ALBI grade on disease-free survival. Last, we did not evaluate the role of microvascular invasion in relation to ALBI grade, which is the work we hope to do in the future.

\section{Conclusion}

In conclusion, ALBI grade is valuable in determining the prognosis of patients with single HCC with tumor size $\leq 7 \mathrm{~cm}$. However, the ALBI grade shows no predictive capability among patients with a single tumor $>7 \mathrm{~cm}$. Patients with a single tumor $>7 \mathrm{~cm}$ may constitute an independent group distinct from the classic BCLC stage A.

\section{Abbreviations}


ALBI: albumin-bilirubin; HCC: hepatocellular carcinoma; OS: overall survival; BCLC: Barcelona Clinic for Liver Cancer; CLIP: Cancer of the Liver Italian Program; AFP: alpha-fetoprotein; HBV: hepatitis B virus; ROC: area under the receiver operating characteristic; JIS: Japan Integrated Staging; MVI: Microvascular invasion.

\section{Declarations}

\section{Ethics approval and consent to participate}

This study was approved by the Institutional Ethical Board of Central South University. Informed consent was waived for this retrospective study.

\section{Consent for publication}

Not applicable.

\section{Availability of data and materials}

The datasets used and/or analyzed during the current study are available from the corresponding author on reasonable request.

\section{Competing interests}

The authors declare that they have no competing interests.

\section{Funding}

This work was supported by the Big Data Project of Xiangya Medical School, Central South University, and the Research Project of Hunan Provincial Health Commission (No. B20180130). The role of the founders was in the design and writing the study.

\section{Authors' contributions}

Conceptualization: HZ and FHK; Data collection: HZ, WHC, ZJZ, LX; Writing-original draft: ZJZ, WHC, HW; Writing-review: HZ, FHK, YW, JJZ; Methodology: YW, LX, HZ. All authors read and approved the final manuscript.

\section{Acknowledgements}

Not applicable.

\section{References}

1. Jordi Bruix, Maria Reig, Morris Sherman. Evidence-based diagnosis, staging, and treatment of patients with hepatocellular carcinoma. Gastroenterology. 2016; 150(4):835-53. 
2. Vitale A, Burra P, Frigo AC, Trevisani F, Farinati F, Spolverato G, Volk M, Giannini EG, Ciccarese F, Piscaglia F, Rapaccini GL, Di Marco M, Caturelli E, Zoli M, Borzio F, Cabibbo G, Felder M, Gasbarrini A, Sacco R, Foschi FG, Missale G, Morisco F, Svegliati Baroni G, Virdone R, Cillo U. Survival benefit of liver resection for patients with hepatocellular carcinoma across different Barcelona Clinic Liver Cancer stages: a multicentre study. J Hepatol. 2015; 62:617-24.

3. EASL-EORTC clinical practice guidelines: management of hepatocellular carcinoma. J Hepatol. 2012; 56:908-43.

4. Hwang S, Lee YJ, Kim KH, Ahn CS, Moon DB, Ha TY, Song GW, Jung DH, Lee SG. The Impact of Tumor Size on Long-Term Survival Outcomes After Resection of Solitary Hepatocellular Carcinoma: Single-Institution Experience with 2558 Patients. J Gastrointest Surg. 2015; 19:1281-90.

5. Zheng YW, Wang KP, Zhou JJ, Zhang ZQ, Xiong L, Wen Y, Zou H. Portal hypertension predicts shortterm and long-term outcomes after hepatectomy in hepatocellular carcinoma patients. Scand J Gastroenterol. 2018; 53:1562-68.

6. Johnson PJ, Berhane S, Kagebayashi C, Satomura S, Teng M, Reeves HL, O'Beirne J, Fox R, Skowronska A, Palmer D, Yeo W, Mo F, Lai P, Inarrairaegui M, Chan SL, Sangro B, Miksad R, Tada T, Kumada T, Toyoda $\mathrm{H}$. Assessment of liver function in patients with hepatocellular carcinoma: a new evidence-based approach-the ALBI grade. J Clin Oncol. 2015; 33:550-8.

7. Kuo YH, Wang JH, Hung CH, Rau KM, Wu IP, Chen CH, Kee KM, Hu TH, Lu SN. Albumin-Bilirubin grade predicts prognosis of HCC patients with sorafenib use. J Gastroenterol Hepatol. 2017; 32:1975-81.

8. Dong ZR, Zou J, Sun D, Shi GM, Ke AW, Cai JB, Sun HC, Qiu SJ, Li T, Zhou J, Zhi XT, Fan J. Preoperative Albumin-Bilirubin Score for Postoperative Solitary Hepatocellular Carcinoma within the Milan Criteria and Child-Pugh A Cirrhosis. J Cancer. 2017; 8:3862-67.

9. Oh IS, Sinn DH, Kang TW, Lee MW, Kang W, Gwak GY, Paik YH, Choi MS, Lee JH, Koh KC, Paik SW. Liver Function Assessment Using Albumin-Bilirubin Grade for Patients with Very Early-Stage Hepatocellular Carcinoma Treated with Radiofrequency Ablation. Dig Dis Sci. 2017; 62:3235-42.

10. Pinato DJ, Sharma R, Allara E, Yen C, Arizumi T, Kubota K, Bettinger D, Jang JW, Smirne C, Kim YW, Kudo M, Howell J, Ramaswami R, Burlone ME, Guerra V, Thimme R, Ishizuka M, Stebbing J, Pirisi M, Carr BI. The ALBI grade provides objective hepatic reserve estimation across each BCLC stage of hepatocellular carcinoma. J Hepatol. 2017; 66:338-46.

11. Tellapuri S, Sutphin PD, Beg MS, Singal AG, Kalva SP. Staging systems of hepatocellular carcinoma: A review. Indian J Gastroenterol. 2018; 37:481-91.

12. Dindo D, Demartines N, Clavien PA. Classification of surgical complications: a new proposal with evaluation in a cohort of 6336 patients and results of a survey. Ann Surg. 2004; 240:205-13.

13. Zou H, Wen Y, Yuan K, Miao XY, Xiong L, Liu KJ. Combining albumin-bilirubin score with future liver remnant predicts post-hepatectomy liver failure in HBV-associated HCC patients. Liver Int. 2018; 38:494-502.

14. Mullen JT, Ribero D, Reddy SK, Donadon M, Zorzi D, Gautam S, Abdalla EK, Curley SA, Capussotti L, Clary BM, Vauthey JN. Hepatic insufficiency and mortality in 1,059 noncirrhotic patients undergoing 
major hepatectomy. J Am Coll Surg. 2007; 204:854-62; discussion 62-4.

15. Liu PH, Hsu CY, Hsia CY, Lee YH, Su CW, Huang YH, Lee FY, Lin HC, Huo TI. Prognosis of hepatocellular carcinoma: Assessment of eleven staging systems. J Hepatol. 2016; 64:601-8.

16. Shao YY, Liu TH, Lee YH, Hsu CH, Cheng AL. Modified CLIP with objective liver reserve assessment retains prognosis prediction for patients with advanced hepatocellular carcinoma. J Gastroenterol Hepatol. 2016; 31:1336-41.

17. Kitai S, Kudo M, Izumi N, Kaneko S, Ku Y, Kokudo N, Sakamoto M, Takayama T, Nakashima O, Kadoya M, Matsuyama Y, Matsunaga T. Validation of three staging systems for hepatocellular carcinoma (JIS score, biomarker-combined JIS score and BCLC system) in 4,649 cases from a Japanese nationwide survey. Dig Dis. 2014; 32:717-24.

18. Hiraoka A, Kumada T, Michitaka K, Toyoda H, Tada T, Ueki H, Kaneto M, Aibiki T, Okudaira T, Kawakami T, Kawamura T, Yamago H, Suga Y, Miyamoto Y, Tomida H, Azemoto N, Mori K, Miyata H, Ninomiya T, Kawasaki H. Usefulness of albumin-bilirubin grade for evaluation of prognosis of 2584 Japanese patients with hepatocellular carcinoma. J Gastroenterol Hepatol. 2016; 31:1031-6.

19. Chan AW, Chong CC, Mo FK, Wong J, Yeo W, Johnson PJ, Yu S, Lai PB, Chan AT, To KF, Chan SL. Applicability of albumin-bilirubin-based Japan integrated staging score in hepatitis B-associated hepatocellular carcinoma. J Gastroenterol Hepatol. 2016; 31:1766-72.

20. Tandon P, Garcia-Tsao G. Prognostic indicators in hepatocellular carcinoma: a systematic review of 72 studies. Liver Int. 2009; 29:502-10.

21. Huang WJ, Jeng YM, Lai HS, Sheu FY, Lai PL, Yuan RH. Tumor size is a major determinant of prognosis of resected stage I hepatocellular carcinoma. Langenbecks Arch Surg. 2015; 400:725-34.

22. Goh BK, Teo JY, Chan CY, Lee SY, Jeyaraj P, Cheow PC, Chow PK, Ooi LL, Chung AY. Importance of tumor size as a prognostic factor after partial liver resection for solitary hepatocellular carcinoma: Implications on the current AJCC staging system. J Surg Oncol. 2016; 113:89-93.

23. Torzilli G, Belghiti J, Kokudo N, Takayama T, Capussotti L, Nuzzo G, Vauthey JN, Choti MA, De Santibanes E, Donadon M, Morenghi E, Makuuchi M. A snapshot of the effective indications and results of surgery for hepatocellular carcinoma in tertiary referral centers: is it adherent to the EASL/AASLD recommendations?: an observational study of the HCC East-West study group. Ann Surg. 2013; 257:929-37.

24. Zhong JH, Pan LH, Wang YY, Cucchetti A, Yang T, You XM, Ma L, Gong WF, Xiang BD, Peng NF, Wu FX, Li LQ. Optimizing stage of single large hepatocellular carcinoma: A study with subgroup analysis by tumor diameter. Medicine (Baltimore). 2017; 96:e6608.

25. Yang LY, Fang F, Ou DP, Wu W, Zeng ZJ, Wu F. Solitary large hepatocellular carcinoma: a specific subtype of hepatocellular carcinoma with good outcome after hepatic resection. Annals of surgery. 2009; 249:118-23.

26. Cho YB, Lee KU, Lee HW, Cho EH, Yang SH, Cho JY, Yi NJ, Suh KS. Outcomes of hepatic resection for a single large hepatocellular carcinoma. World J Surg. 2007; 31:795-801. 
27. Fang KC, Kao WY, Su CW, Chen PC, Lee PC, Huang YH, Huo TI, Chang CC, Hou MC, Lin HC, Wu JC. The Prognosis of Single Large Hepatocellular Carcinoma Was Distinct from Barcelona Clinic Liver Cancer Stage A or B: The Role of Albumin-Bilirubin Grade. Liver Cancer. 2018; 7:335-58.

28. Chan MY, She WH, Dai WC, Tsang SHY, Chok KSH, Chan ACY, Fung J, Lo CM, Cheung TT. Prognostic value of preoperative alpha-fetoprotein (AFP) level in patients receiving curative hepatectomy- an analysis of 1,182 patients in Hong Kong. Transl Gastroenterol Hepatol. 2019; 4:52.

29. Shen J, Liu J, Li C, Wen T, Yan L, Yang J. The Impact of Tumor Differentiation on the Prognosis of HBV-Associated Solitary Hepatocellular Carcinoma Following Hepatectomy: A Propensity Score Matching Analysis. Dig Dis Sci. 2018; 63:1962-69.

30. Han DH, Choi GH, Kim KS, Choi JS, Park YN, Kim SU, Park JY, Ahn SH, Han KH. Prognostic significance of the worst grade in hepatocellular carcinoma with heterogeneous histologic grades of differentiation. J Gastroenterol Hepatol. 2013; 28:1384-90.

31. Zhang ZQ, Xiong L, Zhou JJ, Miao XY, Li QL, Wen Y, Zou H. Ability of the ALBI grade to predict posthepatectomy liver failure and long-term survival after liver resection for different BCLC stages of HCC. World J Surg Oncol. 2018; 16:208.

32. Fang K-C, Kao W-Y, Su C-W, Chen P-C, Lee P-C, Huang Y-H, Huo T-I, Chang C-C, Hou M-C, Lin H-C, Wu JC. The Prognosis of Single Large Hepatocellular Carcinoma Was Distinct from Barcelona Clinic Liver Cancer Stage A or B: The Role of Albumin-Bilirubin Grade. Liver Cancer. 2018; 7:335-58.

33. Zhang XP, Wang K, Wei XB, Li LQ, Sun HC, Wen TF, Chai ZT, Chen ZH, Shi J, Guo WX, Xie D, Cong WM, Wu MC, Lau WY, Cheng SQ. An Eastern Hepatobiliary Surgery Hospital Microvascular Invasion Scoring System in Predicting Prognosis of Patients with Hepatocellular Carcinoma and Microvascular Invasion After R0 Liver Resection: A Large-Scale, Multicenter Study. Oncologist. 2019;

34. Han J, Li ZL, Xing H, Wu H, Zhu P, Lau WY, Zhou YH, Gu WM, Wang H, Chen TH, Zeng YY, Wu MC, Shen $F$, Yang $T$. The impact of resection margin and microvascular invasion on long-term prognosis after curative resection of hepatocellular carcinoma: a multi-institutional study. HPB (Oxford). 2019; 21:962-71.

35. Shen J, Wen J, Li C, Wen T, Yan L, Li B, Yang J, Lu C. The prognostic value of microvascular invasion in early-intermediate stage hepatocelluar carcinoma: a propensity score matching analysis. BMC Cancer. 2018; 18:278.

36. Pawlik TM, Delman KA, Vauthey JN, Nagorney DM, Ng IO, Ikai I, Yamaoka Y, Belghiti J, Lauwers GY, Poon RT, Abdalla EK. Tumor size predicts vascular invasion and histologic grade: Implications for selection of surgical treatment for hepatocellular carcinoma. Liver Transpl. 2005; 11:1086-92.

\section{Tables}

Table 1 Baseline characteristics of $265 \mathrm{HCC}$ patients 


\begin{tabular}{|c|c|c|c|c|}
\hline Variables & $\begin{array}{l}\text { Total cohort } \\
(\mathrm{n}=265)\end{array}$ & $\begin{array}{l}\leq 7 \mathrm{~cm} \\
\text { subgroup } \\
(\mathrm{n}=168)\end{array}$ & $\begin{array}{l}>7 \mathrm{~cm} \\
\text { subgroup } \\
(\mathrm{n}=97)\end{array}$ & $\begin{array}{l}P \text { value } \\
(\leq 7 \mathrm{~cm} \text { vs } \otimes \\
7 \mathrm{~cm})\end{array}$ \\
\hline Age, years ${ }^{a}$ & $51(43-60)$ & $52(41-60)$ & $51(44-60)$ & 0.852 \\
\hline Male gender ${ }^{\mathrm{b}}$ & $231(87.2 \%)$ & $147(87.5 \%)$ & $84(86.6 \%)$ & 0.832 \\
\hline Positive HBsAg ${ }^{b}$ & $228(86.0 \%)$ & $143(85.1 \%)$ & $85(87.6 \%)$ & 0.630 \\
\hline Total bilirubin, $\mu \mathrm{mol} / /^{\mathrm{a}}$ & $13.4(9.8-18.3)$ & $13.3(9.9-19.3)$ & $13.5(9.6-17.9)$ & 0.749 \\
\hline Albumin, $g / l^{a}$ & $\begin{array}{l}38.4(35.6- \\
41.2)\end{array}$ & $39.1(36.4-41.4)$ & $37.9(34.2-40.0)$ & 0.010 \\
\hline ALBI grade $^{b}$ & & & & 0.036 \\
\hline 1 & $147(55.5 \%)$ & $85(50.6 \%)$ & $62(63.9 \%)$ & \\
\hline 2 & $118(44.5 \%)$ & $83(49.4 \%)$ & $35(36.1 \%)$ & \\
\hline Prothrombin time, $\mathrm{s}^{\mathrm{a}}$ & $\begin{array}{l}13.2(12.2- \\
14.4)\end{array}$ & $13.2(12.1-14.3)$ & $13.2(12.3-14.4)$ & 0.934 \\
\hline Platelet count, $\times 10^{9} / \mathrm{I}^{\mathrm{a}}$ & $151(106-210)$ & 135 (93-188) & 195 (135-246) & $<0.001$ \\
\hline $\begin{array}{l}\text { Maximum tumor size, } \\
\mathrm{cm}^{\mathrm{a}}\end{array}$ & $6.0(3.5-9.0)$ & $4.0(3.0-5.5)$ & $10.0(8.0-14.0)$ & $<0.001$ \\
\hline Serum AFP $\geq 400 \mathrm{ng} / \mathrm{ml}^{b}$ & $90(34.0 \%)$ & $46(27.4 \%)$ & $44(45.4 \%)$ & 0.003 \\
\hline Operative time, $\min ^{a}$ & $180(140-210)$ & 170 (136-205) & $180(155-223)$ & 0.015 \\
\hline Blood loss, mla & $300(100-500)$ & $200(100-400)$ & $400(200-1000)$ & $<0.001$ \\
\hline Major hepatectomy ${ }^{b}$ & $42(15.8 \%)$ & $6(3.6 \%)$ & $36(37.1 \%)$ & $<0.001$ \\
\hline $\begin{array}{l}\text { Poor differentiation } \\
\text { grade }^{\text {b }}\end{array}$ & $80(30.2 \%)$ & $42(25.0 \%)$ & 38 (39.2\%) & 0.015 \\
\hline Survival time ${ }^{a}$, mo & $43(25-61)$ & $49(37-62)$ & $26(15-57)$ & $<0.001$ \\
\hline
\end{tabular}

${ }^{a}$ Values are median (interquartile range); ${ }^{b}$ Values are number (\%).

HCC, hepatocellular carcinoma; HBsAg, hepatitis B surface antigen; ALBI, albumin-bilirubin; AFP, afetoprotein. 
Table 2 Prognostic factors for survival in the total cohort

\begin{tabular}{lllll} 
Variables & Univariate analysis & \multicolumn{2}{l}{ Multivariate analysis } & \\
\hline & Hazard ratio & $P$ value & Hazard ratio & $P$ value \\
\hline Age & $0.79(0.51-1.23)$ & 0.298 & & \\
\hline Gender & $1.33(0.75-2.36)$ & 0.331 & & \\
\hline Albumin-bilirubin grade & $2.28(1.57-3.32)$ & $<0.001$ & $2.10(1.43-3.08)$ & $<0.001$ \\
\hline Prothrombin time & $1.46(1.03-2.07)$ & 0.034 & $1.28(0.90-1.83)$ & 0.169 \\
\hline Platelet count & $1.31(0.88-1.95)$ & 0.179 & & \\
\hline Maximum tumor size & $2.08(1.46-2.96)$ & $<0.001$ & $1.72(1.16-2.56)$ & 0.007 \\
\hline Alpha-fetoprotein & $1.42(0.99-2.03)$ & 0.054 & $1.16(0.80-1.70)$ & 0.435 \\
\hline Operation time & $1.51(1.06-2.15)$ & 0.021 & $1.25(0.86-1.83)$ & 0.240 \\
\hline Blood loss & $1.55(1.05-2.28)$ & 0.028 & $1.03(0.67-1.58)$ & 0.891 \\
\hline Major hepatectomy & $1.55(0.99-2.42)$ & 0.054 & $0.95(0.58-1.56)$ & 0.837 \\
\hline Differentiation grade & $1.67(1.17-2.40)$ & 0.005 & $1.47(1.01-2.15)$ & 0.045
\end{tabular}

Table 3 Multivariate analyses of prognostic factors for survival divided by tumor size

\begin{tabular}{lllll} 
Variables & $\leq 7 \mathrm{~cm}$ subgroup & & $>7 \mathrm{~cm}$ subgroup & \\
\hline & Hazard ratio & $P$ value & Hazard ratio & $P$ value \\
\hline Age & $0.81(0.43-1.54)$ & 0.522 & $0.61(0.29-1.29)$ & 0.194 \\
\hline Gender & $1.33(0.59-3.01)$ & 0.498 & $1.61(0.65-3.96)$ & 0.302 \\
\hline Albumin-bilirubin grade & $2.37(1.39-4.05)$ & 0.002 & $1.74(0.95-3.18)$ & 0.072 \\
\hline Prothrombin time & $1.47(0.89-2.44)$ & 0.133 & $0.93(0.53-1.64)$ & 0.798 \\
\hline Platelet count & $1.80(1.07-3.05)$ & 0.027 & $1.12(0.39-3.19)$ & 0.840 \\
\hline Alpha-fetoprotein & $1.45(0.81-2.61)$ & 0.213 & $0.97(0.57-1.67)$ & 0.924 \\
\hline Operation time & $1.10(0.65-1.89)$ & 0.719 & $1.20(0.68-2.12)$ & 0.533 \\
\hline Blood loss & $1.21(0.63-2.32)$ & 0.570 & $0.84(0.47-1.49)$ & 0.548 \\
\hline Differentiation grade & $1.67(0.97-2.86)$ & 0.064 & $1.33(0.77-2.31)$ & 0.311
\end{tabular}


Figures
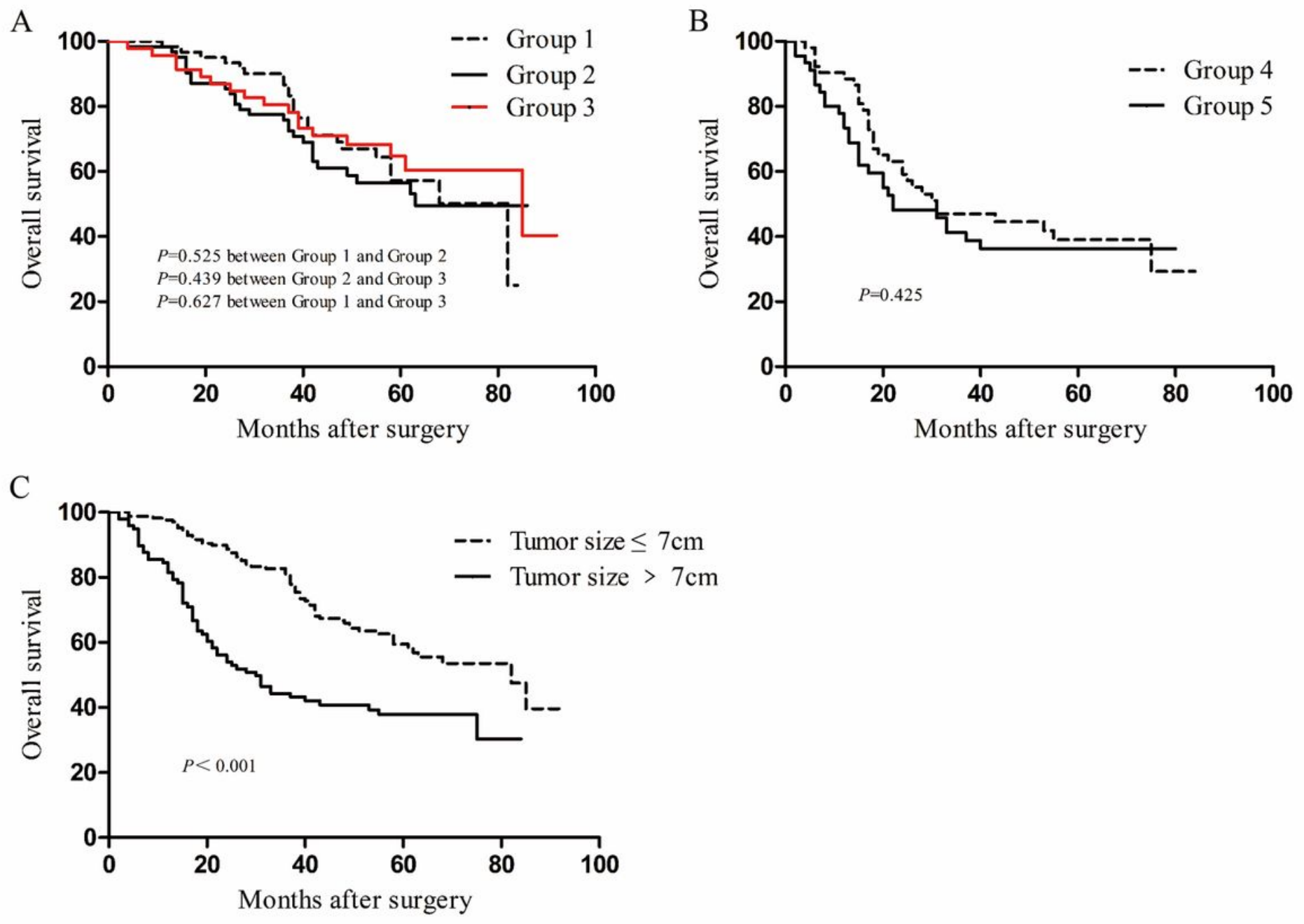

Figure 1

Overall survival of patients with single tumor hepatocellular carcinoma (A) among groups I, II, and III; (B) between groups IV and V; (C) between tumor size $\leq 7 \mathrm{~cm}$ and tumor size $>7 \mathrm{~cm}$ subgroups. 

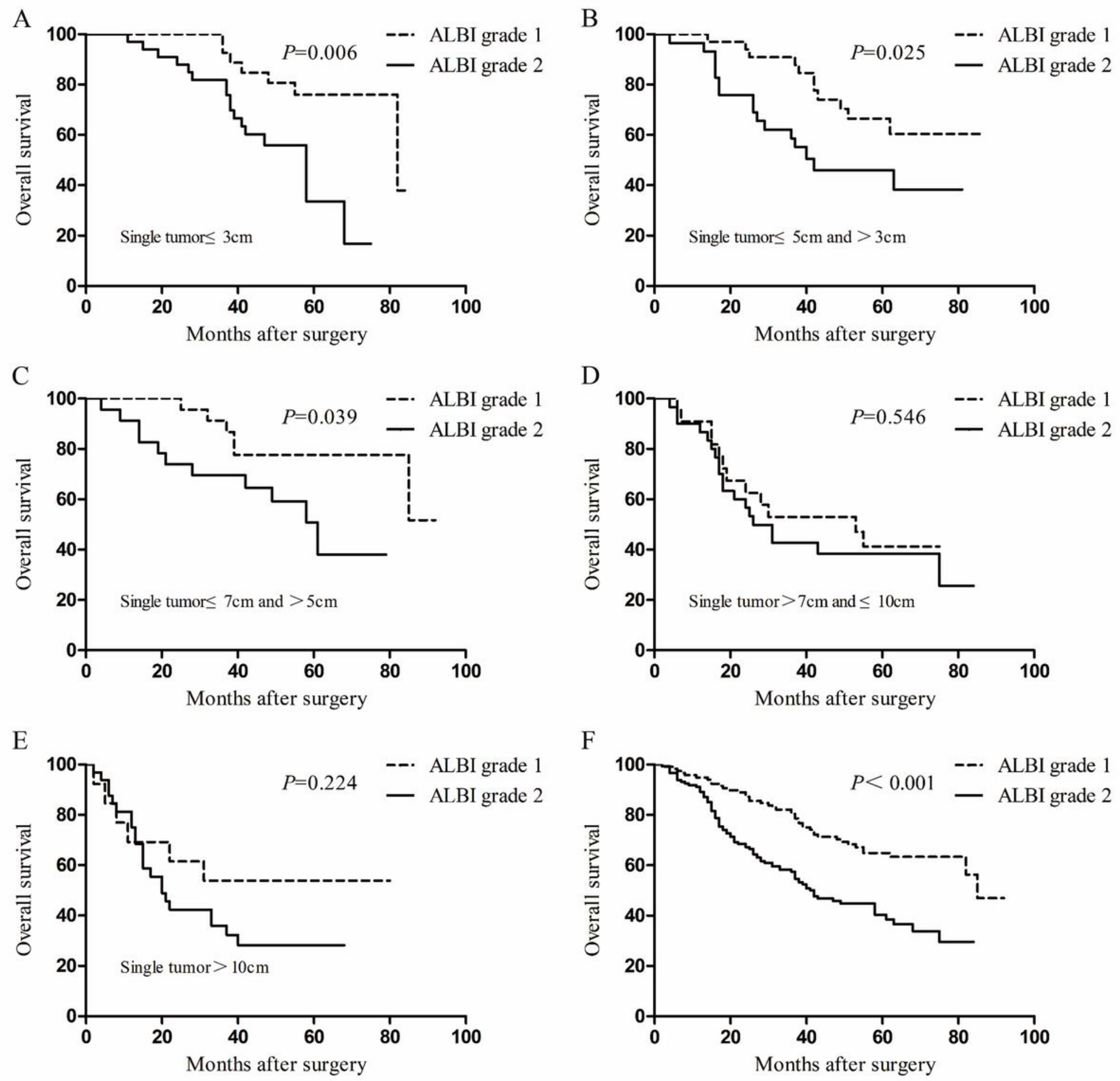

Figure 2

Overall survival of patients with ALBI grades 1 and 2 in the total cohort (F), groups I (A), II (B), III (C), IV $(D)$, and $V(E)$. ALBI, albumin-bilirubin. 


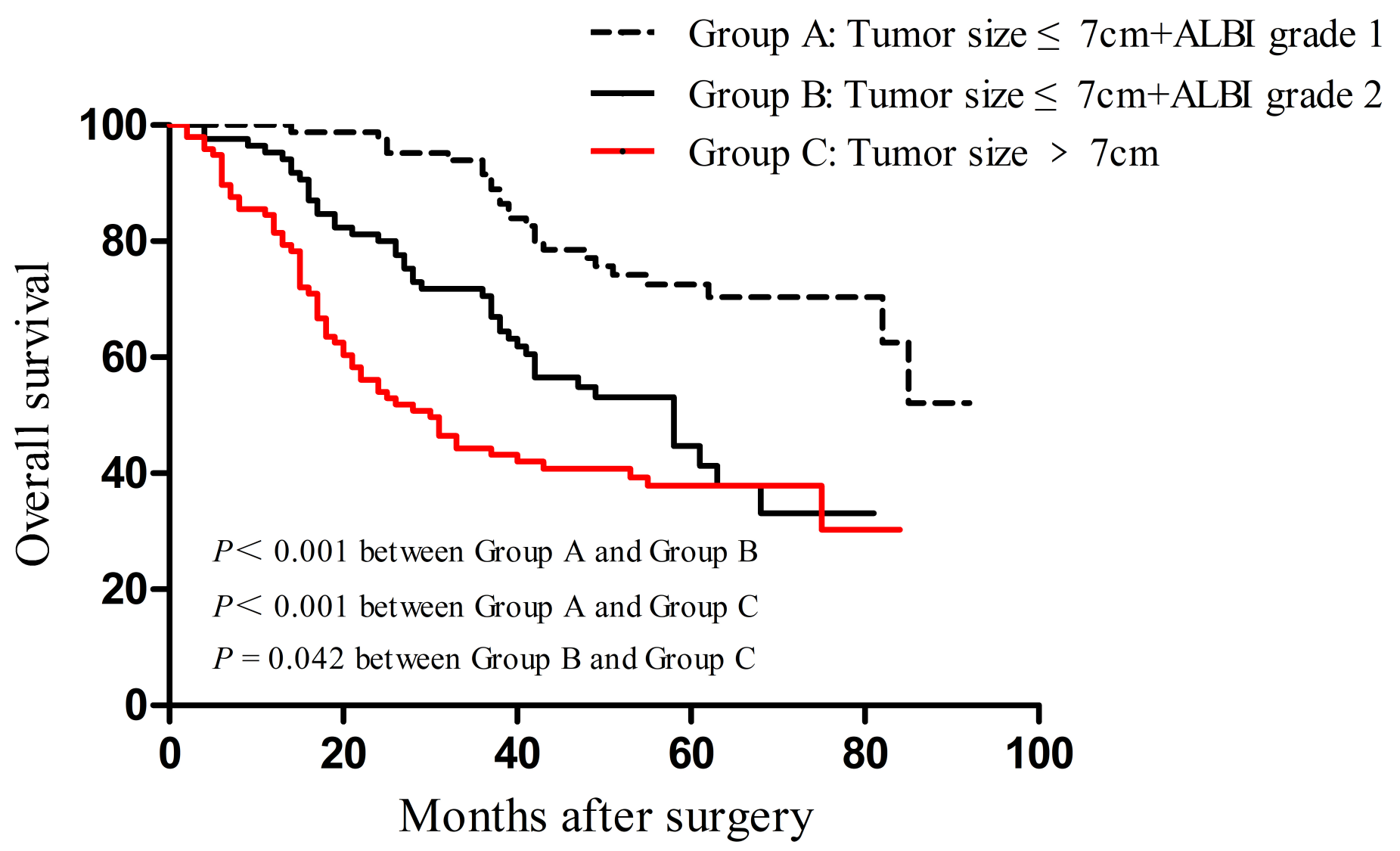

Figure 3

Overall survival curves for patients stratified by ALBI grade and tumor size following hepatic resection. Significant differences were observed in patients between tumor size $\leq 7 \mathrm{~cm}+$ ALBI grade 1 and tumor size $\leq 7 \mathrm{~cm}+A L B I$ grade 2 subgroups $(P<0.001)$; patients in tumor size $\leq 7 \mathrm{~cm}+A L B I$ grade 1 and tumor size $>7 \mathrm{~cm}$ subgroups $(P<0.001)$; and patients in tumor size $\leq 7 \mathrm{~cm}+A L B I$ grade 2 and tumor size $>7 \mathrm{~cm}$ subgroups $(P=0.042)$. ALBI, albumin-bilirubin.
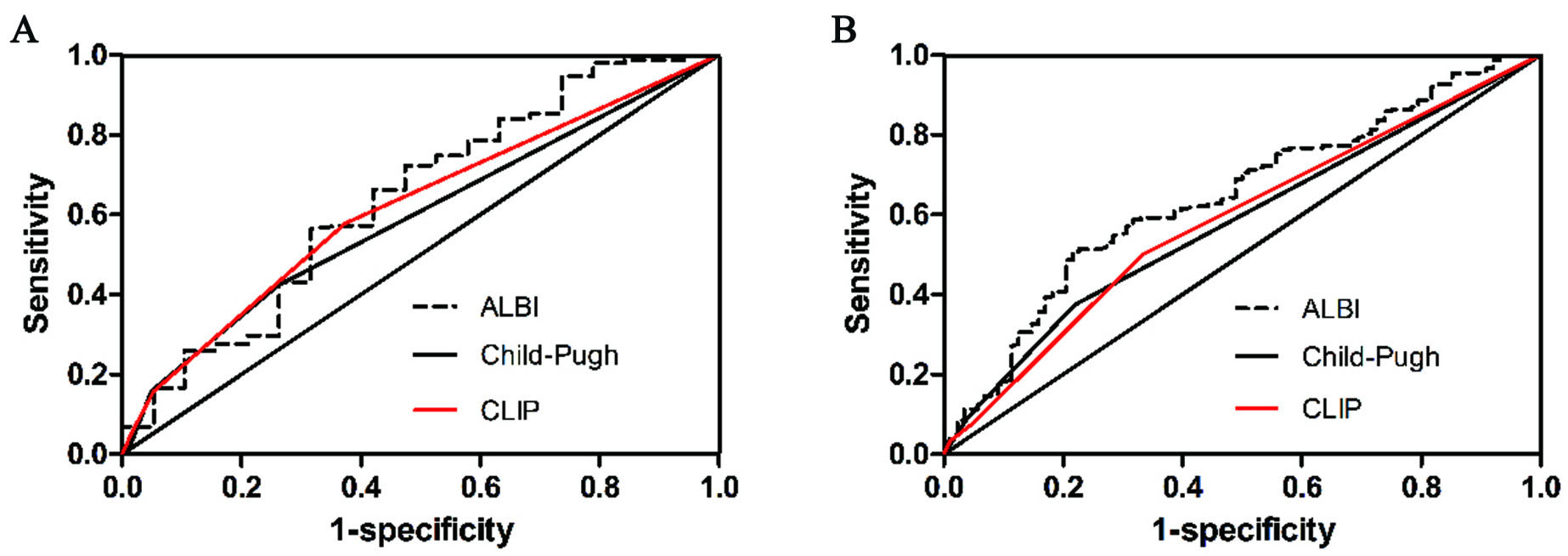

Figure 4 
Comparisons of the area under curve (AUC) for 1-year survival (A) and 3-year survival (B) prediction among the ALBI, Child-Pugh and CLIP systems using ROC curves. 